\title{
Scientific Objectives, Measurement Needs, and Challenges Motivating the PARAGON Aerosol Initiative
}

\author{
by John H. Seinfeld, Ralph A. Kahn, Theodore L. Anderson, Robert J. Charlson, Roger Davies, \\ David J. Diner, John A. Ogren, Stephen E. Schwartz, and Bruce A. Wielicki
}

A systematic, comprehensive aerosol research framework needs to replace the current, fragmented approach.

$\mathrm{T}$ he Progressive Aerosol Retrieval and Assimilation Global Observing Network (PARAGON) concept (Diner et al. 2004) envisions a coordinated and systematic approach for dramatically improving our understanding of aerosol climate impacts and environmental interactions. Among its scientific motivations is the need to establish, with great confidence, the magnitude of direct anthropogenic aerosol influences on climate and the magnitude and sign of indirect aerosol-cloud effects. Modeling of the in-

AFFILIATIONS: SEINFELD-California Institute of Technology, Pasadena, California; KAHN, DAVIES, AND DINER-Jet Propulsion Laboratory, California Institute of Technology, Pasadena, California; ANDERSON AND CHARLSON-University of Washington, Seattle, Washington; OGREN-NOAA Climate Monitoring and Diagnostics Laboratory, Boulder, Colorado; SCHWARTZ-Brookhaven National Laboratory, Upton, New York; WIELICKI—NASA Langley Research Center, Hampton, Virginia CORRESPONDING AUTHOR: David J. Diner, JPL Mail Stop I69237, 4800 Oak Grove Drive, Pasadena, CA 91109

E-mail: djd@jord.jpl.nasa.gov

DOI:I0.1175/BAMS-85-10-1503

In final form 28 July 2004

(C)2004 American Meteorological Society dustrial era temperature record indicates that net aerosol forcing is slightly less, but opposite in sign, than forcing from anthropogenic greenhouse gases (GHGs). However, the uncertainties in aerosol direct and indirect anthropogenic forcing are of the same magnitude as the effects themselves (Penner et al. 2001; Ramaswamy et al. 2001), and are the dominant sources of uncertainty in current estimates of total anthropogenic climate forcing. A major cause of uncertainty is the tremendous tropospheric aerosol variability in space and time. On regional scales, aerosols can have a much greater effect than GHGs, especially at the earth's surface.

Anthropogenic aerosol radiative forcing of climate change has been assessed with forward radiative transfer calculations, constrained by the amount, distribution, and properties of anthropogenic aerosols, and by inverse calculations, which infer anthropogenic aerosol forcing by subtracting greenhouse gas and other known influences from the observed climate record over the industrial period. Using the latter approach, Crutzen and Ramanathan (2003) estimate that the current global net forcing from the combined effect of aerosols on solar radiation backscattering and cloud brightness is about $-1.2 \mathrm{~W} \mathrm{~m}^{-2}$, using as con- 
straints the known global mean radiative forcing by GHGs, the global average surface temperature increase since the midnineteenth century, and the estimated increase in oceanic heat content. Although such estimates of aerosol forcing are within the uncertainty range of those calculated from the forward approach, the forward estimates are also consistent with negative forcing (cooling) by aerosols that is as much as 3 times that inferred by the inverse approach (Anderson et al. 2003a). If aerosol forcing is that great, the $0.6^{\circ} \mathrm{C}$ rise in temperatures over the last century has been driven by a rather small net positive forcing, with the consequence that the earth's climate is much more sensitive than was previously thought. The discrepancy between the uncertainty in forward and inverse models remains a key issue in predicting future climate response to increased concentrations of GHGs, making it critically important to improve and validate three-dimensional global models and to develop more realistic, physically based process representations. Systematic comparison with measurements is the only known way to make models a reliable basis for decisions regarding climate adaptation and mitigation. The PARAGON approach is proposed to make this possible. As the resolution of observations and models improves, a corollary benefit will be the establishment of a worldwide system for studying the impacts of changing aerosol concentrations on air quality.

MEASUREMENT NEEDS. Aerosols are involved in a myriad of processes, as is illustrated schematically in Fig. 1. Their properties are functions of the source type, which determines initial composition; turbu- lence in the boundary layer, which controls mixing height; relative humidity, which affects hygroscopic growth; and time since injection, which establishes the importance of chemical processing, nucleation, condensation, coagulation, and deposition processes, such as sedimentation and precipitation. In the study of indirect effects, it is particularly important to separate aerosol influences on cloud droplets from dynamical effects associated with the local meteorology. These processes operate across many spatial and temporal scales.

Aerosol properties needed for deriving aerosol climate forcing include scattering and absorption coefficients as functions of wavelength, particle size, scattering angle, relative humidity, and height; number-size distribution; size-resolved chemical composition, including major ionic species, elemental and organic carbon, mineral dust, and total mass; spectral optical depth; and number concentration, size distribution, and chemical composition of cloud condensation nuclei (CCN), as a function of supersaturation. These variables are highly interdependent. For example, satellite retrievals of optical depth are strongly influenced by particle absorption, size distribution, and shape.

Aerosol direct forcing results from the scattering and absorption of sunlight. The most important aerosol radiative parameters are extinction coefficient (which, integrated over a vertical column, is the optical depth), single scattering albedo (the fraction of light extinction attributable to scattering), and asymmetry parameter (a measure of the angular distribution of scattered light). Other basic parameters needed are surface reflectivity and cloud cover.

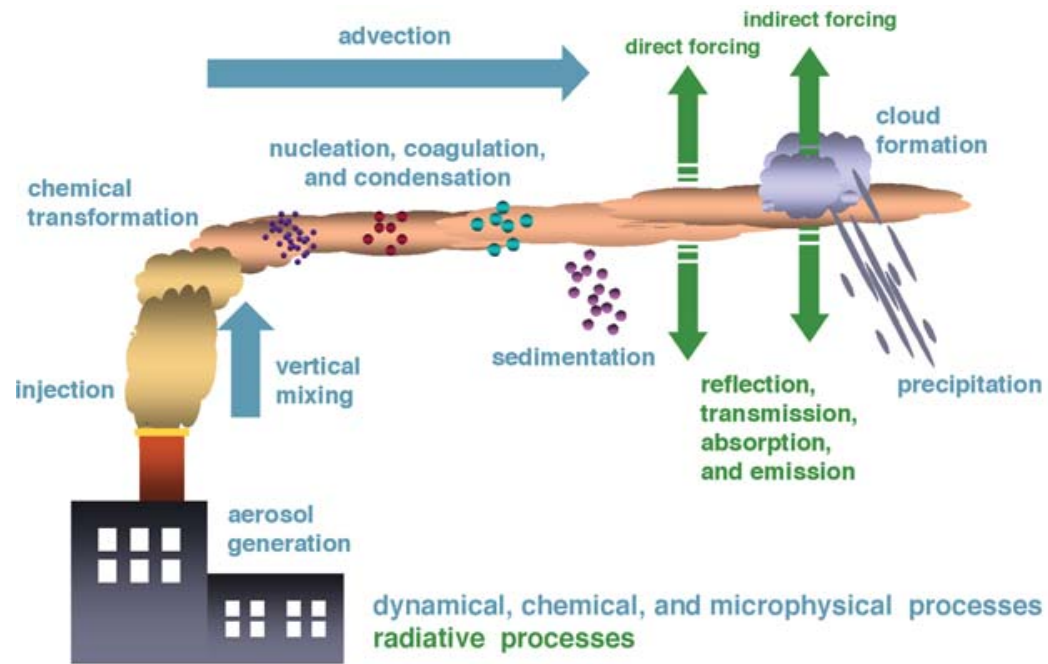

FIG. I. The collection of processes represented in chemical and radiative aerosol models.
Apportioning direct forcing between natural and anthropogenic sources requires measurements of the aerosol chemical composition, with adequate size resolution to allow for the calculation of the light scattering and absorption attributable to the various sources (e.g., dust, sea salt, biomass burning, and industrial emissions). Identification of trace aerosol components, such as metals and organic species, assists in evaluating the relative contributions of natural and anthropogenic sources. The ability to distinguish anthropogenic from natural aerosols also requires adequate knowledge of the background aerosol 
state. Attempts to make this distinction from global remote sensing data rely primarily on particle sizing estimates (Kaufman et al. 2002). However, the submicron tail of natural mineral dust size distributions, for example, can comprise a significant fraction of the total optical depth. Aerosol size distributions also evolve due to gravitational settling and processing by nonprecipitating clouds. Estimates by Pruppacher and Jaenicke (1995) suggest that, on average, aerosols are recycled through clouds three times before removal from the atmosphere. Because background aerosol residence times and associated cloud recycling events are quite uncertain and vary considerably with regional meteorology, separating anthropogenic from natural aerosols based on size is complicated, and measurements must be augmented by models that are sophisticated enough to account for cloud formation and dissipation in conjunction with detailed aerosol physics.

Aerosol indirect forcing results from the interactions of aerosols and clouds. Changes in aerosol composition and concentration lead to changes in the number and size of cloud droplets, which alter cloud reflectivity, lifetime, and resulting precipitation. Statistical relationships between aerosol loading and cloud properties have been derived from Advanced Very High Resolution Radiometer (AVHRR) (Nakajima et al. 2001) and Polarization and Directionality of the Earth's Reflectances (POLDER) data (Bréon et al. 2002). Studies have shown that aerosols can suppress precipitation in smoke from biomass burning (Rosenfeld 1999), urban and industrial pollution (Rosenfeld 2000), and desert dust (Rosenfeld et al. 2001). On the other hand, large sea-salt particles can enhance precipitation (Feingold et al. 1999; Rudich et al. 2002; Rosenfeld et al. 2002). Key measurements that are needed to quantify aerosol indirect forcing include the size distribution and chemical composition of particles that form cloud droplets (i.e., $\mathrm{CCN}$ ), as a function of their supersaturation environment, as well as the resulting size distribution of the cloud droplets. component of

Air quality radiative

effects
Indirect
forcing

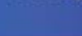

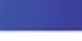

(1)

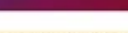

loud drop size istributions, hysical properties, LWP, CCN conc.

Particle chemistry gas phase chemistry

Source locations

chemistry Aircraft
CCN particle samplers

$\begin{array}{ll}\text { Particle sampling } & \text { Aircraft } \\ \text { networks (surface } & \text { CCN partic } \\ \text { and airborne) } & \text { samplers }\end{array}$

Lab. analyses $\begin{array}{ll}\text { Surface and } & \text { Satellite and } \\ \text { satellite gas } & \text { surface cloud }\end{array}$ samplers, radiometers spectrometers (visible to microwave) Aerosol-gas
transformation CCN-cloud activation Aerosol nucleation, growth, and aging models

Data validation and synthesis models vs.
supersaturation

\section{Fig. 2. The evolution of aerosol research and associated measurement needs. \\ Capabilities accumulate from left to right.}

Measurements of key parameters must meet stringent stability and absolute accuracy standards to achieve the desired confidence in aerosol radiative forcing of better than $1 \mathrm{~W} \mathrm{~m}^{-2}$. For example, Ohring et al. (2004) identified accuracy requirements of \pm 0.01 for aerosol optical depth and \pm 0.03 for single scattering albedo, with specified stabilities of one-half these values per decade. Accuracy improvements and new data are necessary to tackle increasingly difficult problems, such as indirect forcing. Figure 2 illustrates the desired progression in capability.

TECHNICAL AND PRACTICAL CHALLENGES. To acquire and use data of sufficient quality for aerosol research, the complex, multidisciplinary nature of the problems must be addressed. We identify four challenges to meeting measurement requirements and building a cohesive dataset.

Data diversity. Three basic approaches have been taken to determining aerosol properties: in situ observations, remote sensing, and three-dimensional numerical modeling. No single, known approach can capture all of the essential information at all relevant scales. In situ observations from aircraft and surface instruments can provide the aerosol mass concentration and its vertical distribution, the aerosol chemical composition, the spectral scattering coefficient, information on aerosol hygroscopic growth, and the spectral single scattering albedo as inferred from sepa- 
rate measurements of scattering and absorption (or extinction) coefficients. Intensive field campaigns produce detailed characterizations of aerosol properties at a few sites over brief intervals, and can yield information on processes involved in chemical and microphysical aerosol evolution. Surface networks generally provide less comprehensive measurements, but cover much longer periods of time. They contain radiometers to measure spectral aerosol optical depth and estimate column-averaged aerosol size distribution, phase function, and single scattering albedo; lidar systems to measure the vertical distribution of aerosols; and chemical sampling and monitoring stations. Satellite imaging radiometers measure regional and global radiances, from which both aerosol optical and microphysical properties, along with radiative fluxes, can be derived. Satellites provide the most practical means to track long-range airmass transport, and to identify a spatial and temporal context (e.g., aerosol source locations). Three-dimensional atmospheric models allow estimates of aerosol radiative forcing from predicted or measured aerosol distributions.

The critical objective of addressing data diversity is to provide a comprehensive and validated physical, chemical, and optical description of the global aerosol system by bringing together qualitycontrolled data from multiple sources. So many domestic and international agencies sponsor data generation, however, that lines of responsibility and a protocol for merging data and verifying quality must be established.

Data quality limitations. Climate studies require greater consistency among observations and models than that which currently exists. Consider the instantaneous aerosol optical depth required to obtain a forcing of $1 \mathrm{~W} \mathrm{~m}^{-2}$. Using a daily average top-of-atmosphere (TOA) aerosol forcing in the absence of clouds of $\sim 30 \mathrm{~W} \mathrm{~m}^{-2}$ per unit optical depth at midvisible wavelengths (Charlson et al. 1991; Boucher et al. 1998), factoring in $60 \%$ cloud cover, and accounting for only half the earth being in sunlight, this optical depth is about 0.04 , comparable to the uncertainty quoted for individual satellite systems, and considerably smaller than the scatter among five remote sensing approaches (Myhre et al. 2004) and between models and observations (Penner et al. 2002). For example, based on the examination of systematic and random errors, Wagener et al. (1997) concluded that the uncertainty in $1^{\circ}$ spatial averages of AVHRR aerosol optical depth retrievals at $0.64 \mu \mathrm{m}$ over the ocean was about $0.03 \pm 33 \%$. Recent analyses of radiances from the Terra Multiangle Imaging SpectroRadiometer (MISR) and
Moderate resolution Imaging Spectroradiometer (MODIS) illustrate that even small $(\sim 3 \%)$ biases in radiometric calibration translate into optical depth uncertainties of a few hundredths (Bruegge et al. 2004; Kahn et al. 2004). On the theoretical side, atmospheric models calculate the relative amounts of natural and anthropogenic aerosols from available emission inventories, and hygroscopic growth is assumed or calculated based on laboratory data and assumed aerosol composition. From these inputs, both the single scattering albedo and angular scattering function are calculated from idealized optical models. Uncertainties in these inputs propagate into estimates of forcing.

Tracking trends in aerosol properties and assessing model performance requires a long-term record with a sustained, self-consistent accuracy. Future satellites, for example, the National Polar-orbiting Operational Environmental Satellite System (NPOESS), will provide some ingredients of a complete spacebased measurement system, though other components, such as systematic satellite aerosol vertical distributions measurements, are absent. The National Aeronautics and Space Administration's (NASA's) satellite missions can demonstrate new measurement capabilities and can even test particular hypotheses; but, these short-term missions, carrying different sensors employing a variety of techniques, make it difficult to identify climate trends. In addition, long-term suborbital aerosol observations are needed to link satellite- and surface-based radiometer and lidar retrieval algorithms and the output of chemical transport models (CTMs).

Aerosol mesoscale variability. Spatial and temporal variability are the primary causes of the large uncertainty in aerosol climate forcing calculations. Tropospheric aerosol amounts and physical and chemical properties are variable on temporal and spatial scales much smaller than those of well-mixed greenhouse gases, such as $\mathrm{CO}_{2}$. This is one reason it is so difficult to quantify anthropogenic aerosol impacts on the climate system. Changes in aerosol distribution over time, caused, for example, by industrialization, urbanization, deforestation, or regional environmental controls, complicate our ability to predict aerosol climatic effects. Thus, a detailed understanding of processes and feedbacks, and the capacity to quantify them on scales spanning orders of magnitude in time and space, are needed.

Comparisons among in situ measurements, satellite data, and atmospheric chemical transport model predictions, raise important practical issues. Anderson et al. (2003b) demonstrated that although there is little variability on scales less than $20 \mathrm{~km}$, and 
for temporal offsets less than about $3 \mathrm{~h}$, a rapid increase in variability occurs over scales from 20 to a few hundred kilometers (see also Benkovitz et al. 1994). This is consistent with the mesoscale nature of dust storms, biomass fires, and megacity plumes (major aerosol sources) and precipitation (a major aerosol sink). All of these examples have physical dimensions around $20-200 \mathrm{~km}$. Aerosol plumes exist on the airmass scale (from several hundred to a few thousand kilometers), but they are not internally homogeneous. Their mesoscale inhomogeneity is due mainly to horizontal mixing times that are slow, compared to aerosol residence times in the lower troposphere; and nonuniform vertical mixing in the presence of large vertical concentration gradients may also play a role.

The performance of CTMs needs to be evaluated not just in terms of how well they predict average aerosol concentrations, but also how well they represent variability. Because mesoscale aerosol variability is generally not resolved by global CTMs, models using horizontal grid cells of $100 \mathrm{~km}$ or more have to account for subgrid-scale variations and correlations. It is critical to understand the processes relevant on temporal scales of hours or less and spatial scales smaller than the grid cells of CTMs and general circulation models (GCMs). For example, many models handle horizontal transport in the free troposphere well, but do not adequately resolve vertical uplift from the boundary layer to the free troposphere. Consequently, a practical framework for merging data acquired over a wide span of spatial and temporal scales is required. Correlations between satellite data and in situ data on the relevant scales also need to be explored, along with closure studies of statistical distributions derived from the respective measurements. Spatial and temporal sampling must be taken into account; for example, surface chemical samples accumulated on a 24 -h or longer basis do not always represent instantaneous aerosol properties measured from satellites. Currently, the lack of in situ data aloft is one major limitation to exploring these key processes.

Cloud ubiquity and heterogeneity. To determine direct aerosol forcing from measurements, clouds must be screened effectively in the aerosol retrieval process. Scattered light from nearby clouds, and the effects of subpixel clouds, are most effectively dealt with through high spatial resolution observations (kilometer-scale or better, with at least one channel observing at a few hundred meters). To date, the spatial resolution of spaceborne near-ultraviolet and po- larimetric data is at least an order of magnitude coarser. Available techniques for screening thick cirrus include using spectral observations within strong gaseous absorptions (Gao et al. 2002); thresholding techniques that rely on one-, two-, or higher-dimensional clustering of TOA visible and infrared window radiances (e.g., Platt 1983; Minnis and Harrison 1984; Arking and Childs 1985; Seze and Desbois 1987; Stowe et al. 1988); clustering of the TOA infrared window radiance and its spatial variability (Coakley and Bretherton 1982); a multiangle band-differenced method (Di Girolamo and Davies 1994); and stereo imaging (Moroney et al. 2002; Zong et al. 2002). Thin cirrus can be observed with simple backscatter lidars and may also be inferred as a component of a multimodal aerosol retrieval.

To evaluate indirect forcing over the entire globe, natural cloud variability and possible correlations with anthropogenic aerosols must be taken into account. As an example, in the eastern United States, southerly winds advect pollution, moisture, and cloud fields, whereas clean, dry cloudless air tends to be associated with winds from the north. The resulting intrinsic correlation between cloudiness and pollution affects efforts to isolate indirect aerosol effects. In addition, meteorological variability tends to mask small aerosol signals in cloud properties, so a longterm record of remotely sensed cloud properties, along with aerosol observations, is needed to separate these contributions. The following variables are important: liquid water content, liquid water path (LWP), cloud geometrical thickness and height, cloud droplet number concentration, effective radius, and cloud lifetime. In general, details of low-cloud and vertical aerosol structure are important when evaluating long-term changes in cloud properties. Lidars need to supplement passive techniques in order to disentangle cloud adjacency effects and to study aerosols above and below clouds. Cloud type changes rapidly on subkilometer spatial scales, and the prevalent cloud heterogeneity (Genkova and Davies 2003) leads to biased cloud optical depth retrievals when based on one-dimensional radiative transfer theory (Loeb and Coakley 1998; Horváth and Davies 2004). Horváth and Davies (2004), in particular, show that at a spatial resolution of $1 \mathrm{~km}$, one-dimensional models match observed multiangular radiances within $\pm 5 \%$ for only about $20 \%$ of the global distribution of clouds. This implies that inferences of cloud water content from radiances require three-dimensional radiative transfer theory for most of the earth's cloud fields. Measurements by ground-based (Kim et al. 2003) and satellite (Harshvardhan et al. 2002) remote 
sensing show that cloud LWP exhibits variability on scales of kilometers and minutes, even for the low stratiform clouds of intermediate optical thickness that are most susceptible to aerosol indirect effects. So, changing LWP, which is one of the major factors affecting cloud optical depth variability, must be quantified as part of the aerosol indirect effect measurements, and satellite observations targeting this research area require higher spatial resolution than is needed to study aerosol direct effects alone.

CONCLUSIONS. Achieving measurement completeness and accuracy sufficient to separate the natural and anthropogenic aerosol influences on climate, and acquiring sufficient understanding with which to disentangle aerosol direct and indirect forcings, represent scientific problems of great complexity. Unambiguous attribution of causes and effects demands measurement accuracies that, in some cases, require developments beyond the current state of the art. Furthermore, the suite of interdependent variables that needs to be observed or modeled is large, and the physical and chemical processes involved span many orders of magnitude in time and space. These factors necessitate an integrated observing and modeling system of commensurate scope. An organized, systematic, and integrated approach, such as that embodied by the PARAGON initiative, offers the best chance of overcoming challenges related to the complexity of the problems being addressed and for resolving practical issues arising from the multidisciplinary nature of the science.

ACKNOWLEDGMENTS. Support from the National Aeronautics and Space Administration, the National Oceanic and Atmospheric Administration, the National Science Foundation, and the U.S. Department of Energy is gratefully acknowledged. The research of R. A. Kahn, R. Davies, and D. J. Diner was conducted at the Jet Propulsion Laboratory, California Institute of Technology, under contract with NASA. T. L. Anderson and R. J. Charlson acknowledge support from the National Science Foundation (Grant ATM-0138250).

\section{REFERENCES}

Anderson, T. L., R. J. Charlson, S. E. Schwartz, R. Knutti, O. Boucher, H. Rodhe, and J. Heintzenberg, 2003a: Climate forcing by aerosols-A hazy picture. Science, 300, 1103-1104.

—, - D. M. Winker, J. A. Ogren, and K. Holmen, 2003b: Mesoscale variations of tropospheric aerosols. J. Atmos. Sci., 60, 119-136.
Arking, A. R., and J. D. Childs, 1985: Retrieval of cloud cover parameters from multispectral satellite measurements. J. Climate Appl. Meteor., 24, 322-333.

Benkovitz, C. M., C. M. Benkovitz, R. C. Easter, S. Nemesure, R. Wagener, and S. E. Schwartz, 1994: Sulfate over the North Atlantic and adjacent continental regions: Evaluation for October and November 1986 using a three-dimensional model driven by observation-derived meteorology. J. Geophys. Res., 99, $20725-20756$.

Boucher, O., and Coauthors, 1998: Intercomparison of models representing direct shortwave radiative forcing by sulfate aerosols. J. Geophys. Res., 103, 16 97916908.

Bréon, F.-M., D. Tanré, and S. Generoso, 2002: Aerosol effect on cloud droplet size monitored from satellite. Science, 295, 834-838.

Bruegge, C. J., W. A. Abdou, D. J. Diner, B. J. Gaitley, M. C. Helmlinger, R. A. Kahn, and J. V. Martonchik, 2004: Validation of the MISR radiometric scale for the ocean aerosol science communities. Proc. Int. Workshop on Radiometric and Geometric Calibration, Gulfport, MS, ISPRS and CEOS. [Available online at www.commission 1.isprs.org/isprs_ceos_ workshop/.]

Charlson, R. J., J. Langner, H. Rodhe, C. B. Leovy, and S. G. Warren, 1991: Perturbation of the northernhemisphere radiative balance by backscattering from anthropogenic sulfate aerosols. Tellus, 43A, 152-163.

Coakley, J. A., and F. P. Bretherton, 1982: Cloud cover from high-resolution scanner data: Detecting and allowing for partially filled fields of view. J. Geophys. Res., 87, 4917-4932.

Crutzen, P. J., and V. Ramanathan, 2003: The parasol effect on climate. Science, 302, 1679-1681.

Di Girolamo, L., and R. Davies, 1994: A banddifferenced angular signature technique for cirrus cloud detection. IEEE Trans. Geosci. Remote Sens., 32, 890-896.

Diner, D. J., and Coauthors, 2004: PARAGON: An integrated approach for characterizing aerosol climate impacts and environmental interactions. Bull. Amer. Meteor. Soc., 85, 1491-1501.

Feingold, G., W. R. Cotton, S. M. Kreidenweis, and J. T. Davis, 1999: Impact of giant cloud condensation nuclei on drizzle formation in marine stratocumulus: Implications for cloud radiative properties. J. Atmos. Sci., 56, 4100-4117.

Gao, B.-C., Y. J. Kaufman, D. Tanré, and R.-R. Li, 2002: Distinguishing tropospheric aerosols from thin cirrus clouds for improved aerosol retrievals using the ratio of $1.38-\mu \mathrm{m}$ and 1.24- $\mu \mathrm{m}$ channels. Geophys. Res. Lett., 29, 1890, doi:10.1029/2002GL015475. 
Genkova, I., and R. Davies, 2003: Spatial heterogeneity of reflected radiance from globally distributed clouds. Geophys. Res. Lett., 30, 2096, doi:10.1029/ 2003 GL018194.

Harshvardhan, S. E. Schwartz, C. M. Benkovitz, and G. Guo, 2002: Aerosol influence on cloud microphysics examined by satellite measurements and chemical transport modeling. J. Atmos. Sci., 59, 714725.

Horváth, Á., and R. Davies, 2004: Anisotropy of water cloud reflectance: A comparison of measurements and 1D theory. Geophys. Res. Lett., 31, L01102, doi:10.1029/2003GL018386.

Kahn, R., and Coauthors, 2004: MISR low-light-level calibration, and implications for aerosol retrieval over dark water. J. Atmos. Sci., in press.

Kaufman, Y. J., D. Tanré, and O. Boucher, 2002: A satellite view of aerosols in the climate system. Nature, 419, 215-223.

Kim, B.-G., S. E. Schwartz, M. A. Miller, and Q. Min, 2003: Effective radius of cloud droplets by groundbased remote sensing: Relationship to aerosol. J. Geophys. Res., 108, 4740, doi:10.1029/2003/D003721.

Loeb, N. G., and J. A. Coakley Jr., 1998: Inference of marine stratus cloud optical depths from satellite measurements: Does 1D theory apply? J. Climate, 11, 215-233.

Minnis, P., and E. F. Harrison, 1984: Diurnal variability of regional cloud cover and clear-sky radiative parameters derived from GOES data. Part II: November 1978 cloud distributions. J. Climate Appl. Meteor., 23, 1012-1031.

Moroney, C., R. Davies, and J.-P. Muller, 2002: Operational retrieval of cloud-top heights using MISR data. IEEE Trans. Geosci. Remote Sens., 40, 15-41.

Myhre, G., and Coauthors, 2004: Intercomparison of satellite retrieved aerosol optical depth over ocean. $J$. Atmos. Sci., 61, 499-513.

Nakajima, T., A. Higurashi, K. Kawamoto, and J. E. Penner, 2001: A possible correlation between satellite-derived cloud and aerosol microphysical parameters. Geophys. Res. Lett., 28, 1171-1174.

Ohring, G., B. Wielicki, R. Spencer, W. Emery, and R. Datla, Eds, 2004: Satellite instrument calibration for measuring global climate change. National Institute of Standards and Technology Rep. NISTIR 7047, 114 pp. [Available online at http://physics.nist.gov/Divisions/Div844/publications/NISTIR7047/ nistir7047.pdf].
Penner, J.E., and Coauthors, 2001: Aerosols, their direct and indirect effects. Climate Change 2001: The Scientific Basis, J. T. Houghton et al., Eds., Cambridge University Press, chapter 5.

—_, and Coauthors, 2002: A comparison of model- and satellite-derived aerosol optical depth and reflectivity. J. Atmos. Sci., 59, 441-460.

Platt, C. M. R., 1983: On the bispectral method for cloud parameter determination from satellite VISSR data: Separating broken cloud from semitransparent cloud. J. Climate Appl. Meteor., 22, 429-439.

Pruppacher, H. R., and R. Jaenicke, 1995: The processing of water vapor and aerosols by atmospheric clouds, a global estimate. Atmos. Res., 38, 283-295.

Ramaswamy, V., and Coauthors, 2001: Radiative forcing of climate change. Climate Change 2001: The Scientific Basis, J. T. Houghton et al., Eds., Cambridge University Press, chapter 6.

Rosenfeld, D., 1999: TRMM observed first direct evidence of smoke from forest fires inhibiting rainfall. Geophys. Res. Lett., 26, 3105-3108.

_ 2000: Suppression of rain and snow by urban and industrial air pollution. Science, 287, 1793-1796.

—, Y. Rudich, and R. Lahav, 2001: Desert dust suppressing precipitation-A possible desertification feedback loop. Proc. Nat. Acad. Sci., 98, 5975-5980.

— , R. Lahav, A. P. Khain, and M. Pinsky, 2002: The role of sea-spray in cleansing air pollution over ocean via cloud processes. Science, 297, 1667-1670.

Rudich, Y., O. Khersonsky, and D. Rosenfeld, 2002: Treating clouds with a grain of salt. Geophys. Res. Lett., 29, 2060, doi:10.1029/2002GL016055.

Seze, G., and M. Desbois, 1987: Cloud cover analysis from satellite imagery using spatial and temporal characteristics of the data. J. Climate Appl. Meteor., 26, 287-303.

Stowe, L. L., C. G. Wellemeyer, T. F. Eck, H. Y. M. Yeh, and the NIMBUS-7 Cloud Data Processing Team, 1988: NIMBUS-7 global cloud climatology. Part 1: Algorithms and validation. J. Climate, 1,445-470.

Wagener, R., S. Nemesure, and S. E. Schwartz, 1997: Aerosol optical depth over oceans: High space and time resolution retrieval and error budget from satellite radiometry. J. Atmos. Oceanic Technol., 14, 577-590.

Zong, J., R. Davies, J.-P. Muller, and D. J. Diner, 2002: Photogrammetric retrieval of cloud advection and top height from the Multi-angle Imaging SpectroRadiometer (MISR). Photogramm. Eng. Remote Sens., 68, 821-829. 